\title{
PROCESSO DE COLETA SELETIVA DE RESÍDUOS SÓLIDOS: UM ESTUDO DE CASO DE SUSTENTABILIDADE NA CIDADE DE SANTA MARIA/RS
}

\author{
S. L. O. ALMEIDA JR ${ }^{1}$, T. K. R. IBDAIWI ${ }^{1}$, D. M. ALMEIDA ${ }^{2}$, L. F. D. LOPES ${ }^{2}$ e V. M. F. COSTA ${ }^{2}$
${ }^{1}$ Faculdade Metodista de Santa Maria/FAMES
${ }^{2}$ Universidade Federal de Santa Maria/UFSM
damiana@mail.ufsm.br ${ }^{*}$ \\ Artigo submetido em julho/2013 e aceito em junho/2015 \\ DOI: $10.15628 /$ holos.2015.1532
}

\section{RESUMO}

O presente artigo tem por objetivo verificar se o processo seletivo utilizado pela Prefeitura Municipal de Santa Maria/RS proporciona sustentabilidade às associações de catadores participantes. A pesquisa se caracteriza como descritiva, do tipo estudo de caso, de cunho bibliográfica, com uso de técnicas de coleta de dados: questionário e observação sistemática. Os resultados comprovam que a população não está separando os resíduos adequadamente visto o grande volume de resíduos não recicláveis encontrados pelas associações. Este fator pode ser revertido com práticas de divulgação e educação, enfatizando que a coleta seletiva é uma alternativa ecologicamente correta, pois evita a contaminação dos solos e água, contribuindo para a sustentabilidade planetária. As associações confirmam que o processo contribui para a sustentabilidade local. Conclui-se que o processo de coleta seletiva de resíduos que a Prefeitura Municipal está adotando proporciona sustentabilidade às associações e aos santa-marienses, pois contribui com o meio ambiente e com a melhoria na qualidade de vida da população.

PALAVRAS-CHAVE: Coleta Seletiva de Resíduos, Desenvolvimento Sustentável, Meio Ambiente, Sustentabilidade.

\section{SELECTIVE PROCESS FOR SOLID WASTE COLLECTION: A CASE STUDY ON SUSTAINABILITY IN THE CITY OF SANTA MARIA/RS}

\begin{abstract}
This paper aims at verifying whether the selection process used by the City of Santa Maria/RS provides sustainability to the local associations of waste collectors. The research is characterized as descriptive, case study, one based on literature review and field survey. For data collection the techniques used were questionnaire and systematic observation. The results show that waste have not been properly separated by the local population since large volumes of non-recyclable ones are found in the associations. This factor can be reversed with dissemination of information and education,
\end{abstract}

emphasizing that the selective collection is an ecologically correct practice, since it avoids the contamination of soil and water, thuscontributing to planetary sustainability. The local associations confirm that the waste selection process contributes to local sustainability. It can be concluded that the selection process of wastecollection undertaken by the City Hall provides sustainability to the associations and also to santa-marienses, since it contributes to the environment and as well as to the improvement of the quality of life of the local population. 


\section{INTRODUÇÃO}

Santa Maria é um município brasileiro situado no Estado do Rio Grande do Sul. Considerada uma cidade média por conter aproximadamente 261.031 habitantes sendo a 5o cidade mais populosa do Estado e com grande influência na região central (IBGE/2010).

Conhecida como "Cidade Cultura", a Prefeitura Municipal de Santa Maria (PMSM) está dando, cada vez mais, atenção para as questões ambientais que circundam o dia-a-dia da população, com ênfase em ações que visam promover a sustentabilidade. São ações com o intuito de angariar o reconhecimento público de sua preocupação com a educação ambiental, responsabilidade social e a sustentabilidade do município.

De acordo com o fiscal de contratos do setor do meio ambiente da Prefeitura Municipal de Santa Maria/RS, essas práticas começaram a ser visualizadas com o novo sistema de coleta seletiva. A destinação correta dos resíduos sólidos é uma das grandes preocupações para o município de Santa Maria, pois conforme a cidade cresce em sua população aumenta também a quantidade de resíduos produzidos e a necessidade de se dar o destino correto para os mesmos. Com isso a Prefeitura Municipal de Santa Maria promove ações para que esses resíduos tenham uma destinação final adequada, sem prejudicar o meio ambiente.

A implementação do novo sistema de coleta de resíduos sólidos do município de Santa Maria consiste em substituir a coleta tradicional feita por caminhão, por contêineres, onde as pessoas depositam os resíduos que, posteriormente, são recolhidos e levados para um local adequado.

Conforme dados da Prefeitura Municipal de Santa Maria, são coletados em torno de 170 toneladas de resíduos sólidos diariamente. Com o intuito de fomentar os aspectos sociais e ambientais, foi dado início ao serviço "Coleta de Inservíveis", que é a retirada dos objetos domésticos de grande porte como sofás, mesas, geladeiras e camas das ruas. O serviço visa recolher esses objetos e colocá-los no aterro sanitário do município para acabar com cenas urbanas muito comuns onde se via resíduos de grande porte no meio das ruas ou ao lado de contêineres o que gera um problema social.

Foi implementado também o serviço de coleta seletiva domiciliar, no intuito de fomentar o processo de reciclagem, ou seja, todos os resíduos coletados por meio desse processo domiciliar é destinado às associações de catadores com registro no município. Além de contribuir na melhoria da qualidade de vida da população santa-mariense, o método visa conscientizar dos problemas ambientais através da educação ambiental proporcionado pela prefeitura nessas associações.

Diante desse contexto o presente estudo visa responder ao seguinte questionamento: 0 sistema de coleta seletiva de resíduo utilizado pela Prefeitura Municipal de Santa Maria proporciona sustentabilidade às associações de catadores deste município? O referido problema nos remete ao objetivo geral do estudo que é verificar se o processo seletivo utilizado pela Prefeitura Municipal de Santa Maria proporciona sustentabilidade às associações de catadores participantes. Já os objetivos específicos consistem em descrever como ocorre o processo seletivo realizado pela Prefeitura Municipal de Santa Maria e analisar o entendimento dos gestores das associações com relação ao processo de coleta seletiva. 
Para a Prefeitura Municipal de Santa Maria, essa atitude de fazer a coleta seletiva de resíduos de todo o município, faz com que se transforme em uma cidade, além de mais limpa e todos os outros benefícios decorrentes dessa coleta, uma cidade que tem uma política ambiental ativa no processo de desenvolvimento. Desta forma, atendendo aos interesses da comunidade de Santa Maria que assim como o restante da população mundial se preocupa com os problemas ambientais e preferem um desenvolvimento focado na sustentabilidade e utilização controlada dos recursos a um desenvolvimento onde há desperdícios e excesso de poluição.

Nesse contexto inserem-se as associações de recicladores que possuem papel fundamental para dar o destino correto para os resíduos. As cinco associações responsáveis pela seleção e reciclagem na cidade de Santa Maria - RS serão estudadas na presente pesquisa.

Assim, percebe-se a relevância do estudo proposto, pois este é assunto de interesse não só local, mas mundial onde os recursos naturais ao serem transformados em algo de utilidade a partir da coleta, transformação e reutilização pelo ser humano sem descartá-lo na natureza. Além disto, é importante ressaltar que o presente estudo pode ainda proporcionar contribuições à gestão ambiental municipal e regional.

\section{GESTÃO AMBIENTAL}

Segundo Valle (2012), a gestão ambiental é entendida como medidas e procedimentos com o objetivo de obter efeitos positivos sobre o meio ambiente quer reduzindo ou controlando os impactos ambientais produzidos por um empreendimento. $O$ autor explica ainda que a gestão ambiental deve ter caráter contínuo no que se refere às melhorias das condições ambientais.

Os principais problemas ambientais provocados pelos humanos decorrem do uso do meio ambiente para obter os recursos necessários para produzir os bens e serviços que estes necessitam e dos despejos de materiais e energia não aproveitados no meio ambiente (BARBIERI, 2011).

Ainda para Barbieri (2011):

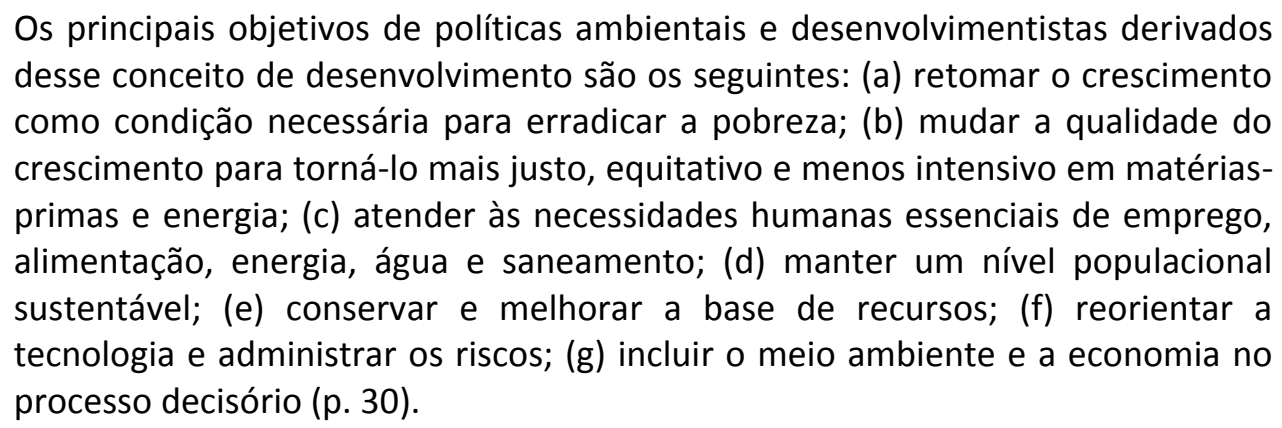

Já para Dias (2005), o objetivo do Sistema de Gestão Ambiental (SGA) é sempre de se obter uma gestão mais eficiente dos recursos e maior satisfação do segmento de mercado em que atua. O autor comenta que é importante a adoção de SGA integrados numa perspectiva mais ampla que envolva sempre a mudança da cultura organizacional da empresa, introduzindo o componente ambiental entre as preocupações da população interna. E que o SGA incorpora de forma sistemática a inovação como componente fundamental e permanente da estrutura organizacional.

Dias (2005, p. 89) explica que: 
Gestão ambiental é a expressão utilizada para se denominar a gestão empresarial que se orienta para evitar, na medida do possível, problemas para o meio ambiente. Em outros termos, é a gestão cujo objetivo é conseguir que os efeitos ambientais não ultrapassem a capacidade de carga do meio onde se encontra a organização, ou seja, obter-se um desenvolvimento sustentável.

Pelo exposto, percebe-se que o principal objetivo da gestão ambiental é curar impactos adversos, ou seja, impedir que estes se manifestem. Agindo antecipadamente para identificar os potenciais impactos e logo propor soluções para que esse não se desenvolva.

Assim, SGA torna-se importante instrumento gerencial para capacitação e criação de condições de competitividade para as organizações, qualquer que seja seu segmento econômico. Sendo uma resposta natural das empresas ao novo cliente, o consumidor ecologicamente correto.

A empresa verde é sinônimo de bons negócios e no futuro tende a ser a única forma de empreender negócios de forma duradoura e lucrativa. O quanto antes as organizações começarem a enxergar o meio ambiente como seu principal desafio e como oportunidade competitiva, maior será a chance de que sobrevivam (TACHIZAWA, 2009).

A gestão ambiental visa integrar plenamente, em cada empresa, essas políticas, programas e procedimentos como elemento essencial de gestão, em todos os seus domínios. Esse processo visa aperfeiçoar continuamente as políticas, os programas e o desempenho ambiental das empresas (ANDRADE et al, 2002, p. 34).

Pelo exposto parece correto afirmar que a SGA é coerente com as ideias relativas ao desenvolvimento sustentável, e que as organizações estão dispondo dessas práticas para atingir os consumidores ecologicamente corretos.

\section{SUSTENTABILIDADE: ALGUMAS CONSIDERAÇÕES CONCEITUAIS}

Nas últimas décadas tem ocorrido uma mudança muito grande no ambiente em que as empresas operam. As empresas que eram vistas apenas como instituições econômicas com responsabilidades referentes a resolver os problemas econômicos fundamentais, o que produzir, como produzir e para quem produzir, tem presenciado o surgimento de novos papéis que devem ser desempenhados, como resultado das alterações no ambiente em que operam (DONAIRE, 2009).

Bulos (2003, p.1353) explica que isto também é ratificado pela Lei n. 6.938/81, pois conforme o art. 225 da Constituição Federal Brasileira de 1988,

Todos têm o direito ao meio ambiente ecologicamente equilibrado, bem de uso comum do povo e essencial à sadia qualidade de vida, impondo-se ao Poder Público e à coletividade o dever de defendê-lo e preservá-lo para os presentes e futuras gerações.

A ideia de sustentabilidade enfoca basicamente que é necessário definir limites às possibilidades de crescimento e traçar um conjunto de iniciativas a fim de levar em conta a existência de interlocutores e participantes sociais relevantes e ativos, reforçando assim um sentimento de corresponsabilidade e de constituição de valores éticos (JACOBI, 2003). 
Para Bina e Vaz (2011) o sistema econômico busca o crescimento e consequentemente o consumo irrestrito. Mesmo esse crescimento, muitas vezes chamado de crescimento em tons verdes, não é garantia de que ocorra para o bem estar geral. É preciso rever as responsabilidades pelas escolhas e estilos de vida, visando o futuro ecologicamente sustentável.

Para um futuro mais agradável à humanidade, a sustentabilidade ambiental é fundamental, pois deve atender as necessidades do presente sem comprometer a possibilidade das gerações futuras em atender às suas próprias necessidades. Ainda para Jacobi $(2003$, p. 7$)$ :

O desenvolvimento sustentável, somente pode ser entendido como um processo no qual, de um lado, as restrições mais relevantes estão relacionadas com a exploração dos recursos, a orientação do desenvolvimento tecnológico e o marco institucional. De outro lado, o crescimento deve enfatizar os aspectos qualitativos, notadamente os relacionados com a equidade, o uso de recursos - em particular da energia - e a geração de resíduos e contaminantes.

A ênfase no desenvolvimento deve projetar-se na superação dos déficits da sociedade, nas necessidades básicas e na mudança dos padrões de consumo, principalmente nos países que são desenvolvidos, para que se possa manter e até mesmo aumentar os recursos-base, sobretudo os agrícolas, energéticos, bióticos, minerais, ar e água (JACOBI, 2003).

A sustentabilidade traz uma visão de desenvolvimento que busca superar o reducionismo e estimula um pensar e fazer sobre o meio ambiente diretamente vinculado ao diálogo entre saberes, a participação, aos valores éticos como valores fundamentais para fortalecer a complexa interação entre sociedade e natureza (JACOBI, 2003).

O desenvolvimento sustentável significa compatibilidade do crescimento econômico, com desenvolvimento humano e qualidade ambiental. Segundo Tayra (2007) o desenvolvimento sustentável preconiza que as sociedades atendam as necessidades humanas em dois sentidos: aumentando o potencial de produção e assegurando a todos a mesmas oportunidades (gerações presentes e futuras).

Percebe-se que não há muita dificuldade para os países em desenvolvimento colocarem em prática a nova cultura de responsabilidade ambiental e sustentabilidade, pois os mesmos já estão se desenvolvendo com a ideia de que toda a sua economia tem que ser voltada para preservação do meio ambiente, ao consumo equilibrado dos recursos naturais e ao desenvolvimento sustentável.

No entanto, os países desenvolvidos podem apresentar maior dificuldade em colocar em prática essa nova cultura, pois esses têm que mudar completamente seus hábitos e costumes, o que não é nada fácil visto que já está implantada desde o início de sua evolução. "Desenvolvimento sustentável é aquele que satisfaz as necessidades e aspirações da geração atual, sem comprometer a capacidade das gerações futuras satisfazerem suas próprias necessidades" (SCHARF, 2004, p.19).

Para Valle (2012) o desenvolvimento sustentável precisa assegurar as necessidades econômicas, sociais e ambientais, sem interferir e comprometer o futuro de nenhuma delas. Conscientizando-se assim, de que é importante ter cuidados com a natureza e seus recursos naturais para que haja um equilíbrio entre o homem e o meio. As organizações também estão mudando a sua visão e adotando a sustentabilidade para o seu desenvolvimento fazendo com que 
não haja sobras exorbitantes de resíduos que possam agredir a natureza e consecutivamente a humanidade.

Floriano (2007, p. 25) corrobora o exposto ao afirmar que "o sistema econômico capitalista baseado no consumismo é incompatível com a evolução da sociedade de maneira sustentável por levar ao esgotamento e deterioração dos recursos ambientais, fazendo ruir a economia". O mesmo autor explica que o "desenvolvimento de uma economia sustentável deve levar em conta a busca do conhecimento e a difusão do mesmo através da educação e da adaptação da cultura á preservação ambiental de forma regionalizada". Floriano (2007) salienta que os países que adotam o sistema econômico capitalista, se quiserem alcançar uma economia sustentável, tem que repensar seus conceitos e mudarem seu sistema de economia para que a sociedade de hoje e de futuramente aproveitem os recursos naturais e satisfaçam as suas necessidades.

Em 1980, o documento "estratégia mundial para a conservação da natureza" definiu sustentabilidade como "uma característica de um processo ou estado que pode manter-se indefinidamente" (IUCN, UNEP, WWF 1980, apud DIAS, 2005).

Desenvolvimento sustentável procura estabelecer uma relação harmônica do homem com a natureza, como centro de um processo de desenvolvimento que deve satisfazer às necessidades e às aspirações humanas. A pobreza é incompatível com o desenvolvimento sustentável e indica a necessidade de que a política ambiental deve ser parte integrante do processo de desenvolvimento e não mais uma responsabilidade setorial fragmentada (p. 31).

Para Dias (2005) é um processo de transformação no qual a exploração dos recursos, a direção dos investimentos, a orientação do desenvolvimento tecnológico e a mudança institucional se harmonizam e reforçam o potencial presente e futuro, a fim de atender as necessidades e aspirações humanas.

O autor comenta que:

O mais importante na abordagem das três dimensões da sustentabilidade empresarial é o equilíbrio dinâmico e necessário e permanente que devem ter, e que tem de ser lembrado em consideração pelas organizações que atuam preferencialmente em cada uma delas: organizações empresariais (econômica), sindicatos (social) e entidades ambientalistas (ambiental). Deve ser estabelecido um acordo entre as organizações de tal modo que nenhuma delas atinja o grau máximo de suas reivindicações e nem o mínimo inaceitável, o que implica num diálogo permanente para que as três dimensões sejam contempladas de modo a manter a sustentabilidade do sistema (p. 39).

Gomes (2008, p.01), complementa o abordado por Dias (2005) ao expor que:

Ao fazermos um balanço histórico das relações homem-natureza, homemhomem, a lição mais proveitosa que podemos tirar neste momento, será, sem dúvida, a necessidade de uma mudança na postura humana de lidar com o meio natural. Pensávamos que os recursos naturais eram inesgotáveis, que estariam sempre à nossa disposição em quantidade ilimitada. Acreditávamos que a Terra é que provia e mantinha a vida; aos humanos cabia apenas explorá-la, tirando o máximo proveito, como quem saboreia um sorvete e lança a casca fora. Descobrimos agora que, após o ato da criação, vem outro tão importante quanto 
o primeiro, que é a recriação contínua que mantêm a vida na terra e que é desenvolvido pelos seres vivos.

Andrade et al (2002) afirmam que somente a partir do século passado já na iminência de um colapso do meio ambiente, foi que as ONG's, governos, empresas e população começaram a ter a exata proporção da destruição, se iniciou uma guerra sem precedentes contra os predadores do meio ambiente.

Uma sociedade sustentável é aquela que satisfaz suas necessidades sem diminuir as perspectivas das gerações futuras. Consideram ainda que a preservação do meio ambiente nos dias de hoje é considerada uma das prioridades de qualquer organização.

\subsection{A Contaminação do Meio Ambiente}

Os maiores problemas causados pela industrialização é a destinação dos resíduos provenientes do processo produtivo, que afetam o meio ambiente natural e a saúde humana. Segundo uma definição proposta pela Organização Mundial de Saúde, um resíduo é algo que seu proprietário não mais deseja, em um dado momento e em determinado local, e que não tem um valor de mercado (VALLE, 1995). Já Barbieri (2011) diz que resíduo é o resto, o que sobra de algum processo ou atividade, podendo se apresentar nos estados sólidos, líquidos e gasosos. Souza e Silva (1997) explicam que uma vez caracterizados, os resíduos poderão ser cadastrados e classificados, identificando se a solução mais adequada, caso a caso, para o seu tratamento ou disposição final.

A norma brasileira de resíduos sólidos, NBR 10004:1978, classifica-os em três classes distintas, conforme Quadro 1.

Quadro 1 - Três classes de resíduos e seus conceitos

\begin{tabular}{l|l}
\hline \multicolumn{1}{c|}{ RESÍDUOS } & \multicolumn{1}{c}{ CONCEITO } \\
\hline \multirow{3}{*}{ Perigosos } & $\begin{array}{l}\text { Resíduos não inertes e resíduos inertes. Essa divisão decorre da constatação de que, } \\
\text { de todo o volume de resíduos gerados pelo homem, somente uma parcela } \\
\text { relativamente pequena requer maior rigor em seu monitoramento e controle. }\end{array}$ \\
\hline Não perigosos & $\begin{array}{l}\text { Podem ser classificados como inertes e não inertes e sua disposição é relativamente } \\
\text { simples e pouca onerosa. Os resíduos domiciliares e uma parcela importante dos } \\
\text { resíduos industriais são resíduos não perigosos. }\end{array}$ \\
\hline Sólidos perigosos & $\begin{array}{l}\text { São aqueles resíduos ou mistura desses, que em função de suas características, } \\
\text { podem apresentar risco à saúde pública, provocando ou contribuindo para um } \\
\text { aumento de mortalidade ou incidência de doenças, podendo ainda trazer efeitos } \\
\text { adversos ao meio ambiente, quando manuseados ou dispostos de forma } \\
\text { inadequada. }\end{array}$ \\
\hline
\end{tabular}

Fonte: Adaptado com base na NBR 10004:1978

O conceito de resíduo perigoso se baseia, portanto no grau de nocividade que representa para o homem e o meio ambiente e pode variar de acordo com a legislação ambiental estabelecida em cada país (SOUZA e SILVA, 1997).

Diversas expressões têm sido utilizadas para designar esses resíduos que requerem maior cuidado: resíduos tóxicos, resíduos especiais, resíduos químicos, resíduos perigosos. Alguns resíduos perigosos são tratados separadamente pela legislação da maioria dos países e recebem denominações próprias, como resíduos hospitalares (que incluem resíduos infectantes e resíduos farmacêuticos) e os resíduos radioativos (BARBIERI, 2011). 
Solventes, pesticidas e suas embalagens usadas, lodos de estações de tratamento, cinzas e alguns tipos de escórias, produtos tóxicos, tintas, pigmentos inorgânicos, combustíveis, alcatrões, sais de têmpera com cianetos, substâncias contendo chumbo, mercúrio e outros metais pesados são alguns exemplos de materiais que se enquadram na classificação de resíduos perigosos (VALLE, 2012).

Como consequência para enfrentar a carência de locais adequados para disposição de resíduos, iniciou-se a busca por soluções mais eficazes do que a simples deposição dos mesmos no meio ambiente. Essas soluções são escolhidas a partir de abordagens distintas e expressas pelas seguintes providências, conforme Quadro 2 (VALLE, 1995).

Quadro 2 - Soluções para destinação de resíduos e respectivas providências

\begin{tabular}{l|l}
\hline \multicolumn{1}{c|}{ SOLUÇÕES } & \multicolumn{1}{c}{ PROVIDÊNCIAS } \\
\hline Minimização & $\begin{array}{l}\text { Preventiva, orientada para reduzir o volume e o impacto causado pelos resíduos. A } \\
\text { minimização é feita através de modificações no processo produtivo, ou pela adoção } \\
\text { de tecnologias limpas, mais modernas que permitem, em alguns casos, eliminar } \\
\text { completamente a geração de materiais nocivos. Não se considera a redução do } \\
\text { volume de resíduos como minimização sem a redução de sua toxicidade. }\end{array}$ \\
\hline Reciclagem & $\begin{array}{l}\text { Reciclar é refazer o ciclo, permite trazer de volta à origem, sob a forma de matérias- } \\
\text { primas, aqueles materiais que não se degradam facilmente e que podem ser } \\
\text { reprocessados, mantendo suas características básicas. }\end{array}$ \\
\hline $\begin{array}{l}\text { Recuperação } \\
\text { resíduos gerados dos }\end{array}$ & $\begin{array}{l}\text { Abordagem orientada para extrair valores materiais ou energéticos dos resíduos, } \\
\text { contribuindo para reduzir os custos de destinação dos resíduos. }\end{array}$ \\
\hline
\end{tabular}

Fonte: Adaptado de Valle (1995)

É importante que se tenha conhecimento das possíveis soluções e as providências possíveis para cada uma delas.

\section{METODOLOGIA}

Esse estudo se caracteriza com uma pesquisa de cunho bibliográfica e descritiva. Gil (2010, p.48) define, que "a pesquisa bibliográfica é desenvolvida a partir de material já elaborado, constituído principalmente de livros e artigos científicos". Portanto a pesquisa bibliográfica nos permite explorar por meio do material existente, novas alternativas de estudo, proporcionando a análise de um determinado problema, com uma visão diferenciada do tema.

Já a pesquisa descritiva visa observar, registrar e analisar os fenômenos sem, entretanto, entrar no mérito do seu conteúdo. Esse tipo de pesquisa não tem interferência do investigador que apenas procura descobrir a frequência com que os fenômenos acontecem (OLIVEIRA, 2001). Visa também, descrever as características de determinada população ou fenômeno ou o estabelecimento de relações entre variáveis.

\subsection{Delineamento}

O presente estudo utilizou como estratégia o estudo de caso da Prefeitura Municipal de Santa Maria. Segundo Yin (2005) o método estudo de caso caracteriza-se pelo estudo de um ou mais objetivos, permitindo um amplo conhecimento a respeito. A pesquisa contou também com cinco entidades: ASMAR, ARCA, ARPS, Noêmia Lazzarini e ARSELE, conforme demonstra o Quadro 3. 
Quadro 3 - Entidades participantes da pesquisa

\begin{tabular}{|c|c|c|}
\hline Entidade & Breve descrição & Entrevistado \\
\hline $\begin{array}{l}\text { ASMAR - Associação dos } \\
\text { Selecionadores de } \\
\text { Materiais Recicláveis }\end{array}$ & $\begin{array}{l}\text { Sede: Rua Israel Seligmann, no } 660 \text { - Bairro Senhora de Lourdes. } \\
\text { Muito bem estruturada, possui o maquinário necessário para } \\
\text { triturar e prensar. Conta com o auxilio de dois caminhões, um da } \\
\text { própria associação e o outro disponibilizado pela PMSM. } \\
\text { Responsável pelo recolhimento dos resíduos nos domicílios de } \\
\text { Santa Maria e a distribuição às associações participantes. } \\
\text { Está cadastrada para recebimento dos resíduos seletivos. } \\
\text { Possui vinte colaboradores. }\end{array}$ & E1 \\
\hline $\begin{array}{l}\text { ARCA - Associação de } \\
\text { Recicladores de Camobi }\end{array}$ & $\begin{array}{l}\text { Sede: Rua Nércio de Oliveira, no } 75 \text { - Bairro Camobi. } \\
\text { Estrutura física pequena, porém conta com todo o maquinário } \\
\text { necessário para triturar e prensar. Possui cinco colaboradores. }\end{array}$ & E2 \\
\hline $\begin{array}{l}\text { ARPS - Associação de } \\
\text { Recicladores Por do Sol }\end{array}$ & $\begin{array}{l}\text { Sede: Rua 'E', no } 09 \text { - Vila Pôr do Sol. } \\
\text { Estrutura física precária (de madeira como um galpão). Possui } \\
\text { maquinário para coletar, selecionar, picar e prensar. Conta com o } \\
\text { auxilio de um caminhão disponibilizado por uma empresa da } \\
\text { cidade. } \\
\text { Possui oito colaboradores. }\end{array}$ & E3 \\
\hline $\begin{array}{l}\text { Associação de Catadores } \\
\text { e Reciclagem Noêmia } \\
\text { Lazzarini }\end{array}$ & $\begin{array}{l}\text { Sede: Rua Trav. Domingues, no } 138 \text { - Bairro Divina Providência. } \\
\text { A associação não dispõe maquinário para auxilio. O espaço físico é } \\
\text { pequeno e a estrutura é muito precária, feito de madeira. }\end{array}$ & E4 \\
\hline $\begin{array}{l}\text { ARSELE - Associação de } \\
\text { Reciclagem Seletiva de } \\
\text { Lixo Esperança }\end{array}$ & $\begin{array}{l}\text { Sede: Av. Borges de Medeiros, no } 511 \text { - Bairro Salgado Filho. A } \\
\text { estrutura física é ampla, com maquinário para recortar e prensar. } \\
\text { Possui dez colaboradores. }\end{array}$ & E5 \\
\hline
\end{tabular}

Fonte: Elaborado pelos autores

A presente pesquisa caracterizou-se como qualitativa, pois não emprega dados estatísticos como foco do processo de análise de um problema. A pesquisa qualitativa tem como objetivo situações complexas ou estritamente particulares (OLIVEIRA, 2001).

As análises foram feitas a partir dos dados coletados por meio de questionários e entrevistas semiestruturadas, com os responsáveis das cooperativas que recebem os resíduos para reciclagem.

\subsection{Coleta e Análise de Dados}

Neste estudo se realizou a análise de conteúdo no qual são estabelecidas categorias " $a$ priori" com base em Bardin (2010) com o intuito de responder o objetivo central do estudo. Para a coleta dos dados utilizou-se de um roteiro de entrevista com perguntas abertas no qual foi aplicado aos responsáveis das cinco associações de Santa Maria com o intuito responder aos questionamentos do estudo.

Quadro 4 - Questionamentos realizados aos entrevistados das associações

\begin{tabular}{l} 
Questionamentos - Responsáveis pelas Associações \\
\hline Como são realizados os processos de coleta e reciclagem da cidade? \\
\hline Qual o entendimento da participação da Prefeitura Municipal de Santa Maria no processo de coleta seletiva \\
na cidade? \\
\hline Se o processo traz sustentabilidade às associações. \\
\hline E quais aspectos poderiam ser melhorados às associações? \\
\hline Como aumentar a participação da comunidade nesse processo?
\end{tabular}

Fonte: Elaborado pelos autores 
Também se utilizou um roteiro de entrevista com perguntas abertas aplicada a Prefeitura Municipal de Santa Maria, representada pelo fiscal de contratos do setor do meio ambiente. Os questionamentos abrangeram os seguintes assuntos.

Quadro 5: Questionamentos realizados ao fiscal de contrato do Setor de Meio Ambiente da Prefeitura Municipal de Santa Maria (PMSM)

\begin{tabular}{l}
\hline \multicolumn{1}{c}{ Questionamentos - Fiscal de Contratos do Setor de Meio Ambiente da PMSM } \\
\hline $\begin{array}{l}\text { Razões pelo qual a Prefeitura Municipal de Santa Maria resolveu aderir a esse novo sistema de coleta seletiva } \\
\text { de resíduos. }\end{array}$ \\
\hline Como funciona o sistema de coleta seletiva de resíduos em Santa Maria? \\
\hline O novo sistema de coleta por contêineres e coleta seletiva proporcionam visibilidade à cidade? \\
\hline O processo agendado de coleta desperta conscientização ecológica nos Cidadãos e de que forma? \\
\hline Quais são os principais ganhos para a cidade?
\end{tabular}

Fonte: Elaborado pelos autores

Os dados coletados por meio das entrevistas foram explorados por meio da análise de conteúdo. Dessa forma foram categorizadas unidades de análise para interpretação dos dados. Cabe explicar também que se realizou análise observando-se o que ensina Tachizawa \& Mendes (2000, p.46), ou seja, "a comparação dos dados obtidos e informações descritas com o suporte teórico e conceitual da fundamentação teórica". Os resultados obtidos serão apresentados no próximo capítulo.

\section{ANÁLISE DOS RESULTADOS}

Neste item são apresentados os resultados obtidos no presente estudo com base no objetivo proposto e na literatura científica sobre o tema em questão. Inicialmente, apresenta-se a descrição do processo de coleta seletiva em Santa Maria/RS, seguido dos processos de coleta e reciclagem dos resíduos, o entendimento dos gestores, a questão de sustentabilidade. Assim como, os aspectos a serem melhorados, as percepções sobre o aumento da participação da população de Santa Maria na coleta seletiva de resíduos e, por fim, o processo seletivo de coleta sob a ótica da Prefeitura Municipal de Santa Maria/RS.

\subsection{Descrição do Processo de Coleta Seletiva em Santa Maria/RS}

Segundo os responsáveis pelas associações e o fiscal de contratos do setor do meio ambiente da Prefeitura Municipal de Santa Maria o processo de coleta seletiva é desenvolvido com a participação da população e contribuintes da cidade de Santa Maria.

Os cidadãos ligam para a "linha verde" do setor do meio ambiente da prefeitura e efetuam o seu cadastro. Com o cadastro efetuado, o contribuinte escolhe o melhor dia e horário para que haja o recolhimento dos resíduos em sua residência.

A prefeitura repassa a lista dos contribuintes cadastrados para a Associação dos Selecionadores de Materiais Recicláveis (ASMAR), pois essa preencheu todos os requisitos constantes em contrato ganhando a licitação onde ficará responsável pelo recolhimento do resíduo seletivo domiciliar da cidade, e a distribuição às associações participantes por pelo menos um ano, podendo ser renovado após esse período.

A ASMAR dirige-se até as residências nos horários e dias marcados para a coleta do resíduo seletivo. Ao efetuar a coleta na residência de todos os contribuintes, o caminhão da associação 
desloca-se até a prefeitura. No local são feitas as medidas dos resíduos, pois a associação recebe da prefeitura o valor de acordo com os metros cúbicos de resíduos. Esse valor é pago ao final de cada mês.

Efetuada a medida dos resíduos na prefeitura, a ASMAR encaminha os resíduos sólidos selecionados para as associações cadastradas no sistema de coleta seletiva onde as mesmas tornam-se responsáveis pela separação, reciclagem e destinação dos resíduos. O caminhão utilizado no processo de coleta e destinação dos resíduos de Santa Maria é disponibilizado pela prefeitura. Cada associação é beneficiada uma vez por semana com a doação da coleta seletiva. Todas às associações participantes cadastraram-se diretamente na Prefeitura Municipal de Santa Maria e foram escolhidas através de requisitos constantes em contrato. As associações cadastradas são beneficiadas pelo sistema de coleta seletiva uma vez por semana, cada associação recebe os resíduos secos coletado na cidade.

O recebimento dos resíduos coletados é feito pelo responsável da associação beneficiada no dia da semana, que por sua vez descarrega o caminhão colocando os resíduos dentro de sua sede. Logo após começam a realizar o processo de separação e enfim dão a destinação correta para os resíduos. O cadastro das associações e o recebimento dos resíduos coletados são importantes para fins de controle para a prefeitura.

O processo apresentado demonstra que a Prefeitura Municipal de Santa Maria está comprometida com o desenvolvimento sustentável do município visto que "desenvolvimento sustentável é aquele que satisfaz as necessidades e aspirações da geração atual, sem comprometer a capacidade das gerações futuras satisfazerem suas próprias necessidades" (SCHARF, 2004, p.19).

Com esse sistema a prefeitura poderá obter melhores informações a respeito da participação da população de Santa Maria em corroborar com a coleta seletiva e também se às associações participantes estão satisfeitas com o novo processo e se este está proporcionando sustentabilidade às associações.

\subsection{Processos de Coleta e Reciclagem de Resíduos Sólidos}

Os responsáveis pelas associações ao serem questionados como são realizados os processos de coleta e reciclagem de resíduos sólidos da cidade responderam conforme o quadro 6.

Quadro 6 - Respostas dos gestores das associações a respeito do processo de coleta e reciclagem de resíduos sólidos

\begin{tabular}{c|l}
\hline Entrevistados & \multicolumn{1}{c}{ Respostas } \\
\hline E1 & $\begin{array}{l}\text { Fazemos a nossa coleta através de um caminhão, que é próprio da associação e também } \\
\text { recebemos todas às terças-feiras o caminhão da prefeitura que se encontra sob nossa gestão, } \\
\text { pois ganhamos a licitação para fazermos a coleta seletiva na cidade e a distribuição às outras } \\
\text { associações. Na sede da associação separamos os resíduos, colocamos na prensa, o que for } \\
\text { preciso para juntá-los em lotes e vendemos. }\end{array}$ \\
\hline \multirow{5}{*}{ E2 } & $\begin{array}{l}\text { A separação dos resíduos é feita aqui na associação e depois colocamos nas máquinas o que é } \\
\text { preciso prensar como os papelões e as latinhas, mas tudo separado. Depois de tudo pronto } \\
\text { vendemos para a empresa Sul Brasil. Antigamente recebíamos os resíduos dos catadores, mas } \\
\text { atualmente só recebemos da ASMAR que é a responsável por coletar o resíduo seco na cidade e } \\
\text { encaminhar às associações. Recebemos esses materiais todas as quintas-feiras. }\end{array}$ \\
\hline $\begin{array}{l}\text { Buscávamos os resíduos de carrocinha, mas hoje em dia temos um caminhão que uma empresa } \\
\text { nos emprestou para fazermos a coleta do reciclável na cidade. A prefeitura também traz todas }\end{array}$ \\
\hline
\end{tabular}




\begin{tabular}{c|l}
\hline \multirow{2}{*}{ E4 } & $\begin{array}{l}\text { às sextas-feiras os resíduos seletivos para nós. Quando chega fizemos a separação de tudo e } \\
\text { colocamos na prensa para juntar e ficar mais organizado e por último vendemos. }\end{array}$ \\
\hline E5 & $\begin{array}{l}\text { Saímos cedo para coletar os resíduos recicláveis nas ruas e todas às quartas-feiras o caminhão } \\
\text { da prefeitura passa aqui e deixa os resíduos secos que eles coletam na cidade. Infelizmente não } \\
\text { temos máquinas, como as prensas, para organizar melhor o espaço que já é pouco aqui, mas } \\
\text { separamos tudo e colocamos em sacos grandes para depois vendê-los. }\end{array}$ \\
\hline $\begin{array}{l}\text { Buscamos os resíduos recicláveis com os carrinhos, e o caminhão da prefeitura passa uma vez } \\
\text { por semana, todas às segundas-feiras. Nós separamos aqui na associação, colocamos na prensa } \\
\text { para juntar por tipos separados e vendemos. }\end{array}$ \\
\hline
\end{tabular}

Fonte: Dados da pesquisa

Percebe-se que todas às associações recebem o resíduo reciclável que é coletado na cidade. Às associações fazem a separação e dão a destinação correta a esses resíduos. Esse processo de retornar a sucata em matéria prima e produto final por meio de industrialização, ou seja, a reciclagem é de extrema importância para o município e para os moradores, pois disponibiliza a cidade, a destinação ecologicamente correta dos resíduos produzidos pelos cidadãos e mostra uma cidade preocupada com a questão ambiental. Com esse sistema de coleta haverá aumento da participação da população em separar os resíduos recicláveis dos não recicláveis. Segundo Zaneti (1997, p.14), "para reduzir o impacto no meio ambiente, tanto na acumulação do lixo, como no esgotamento das fontes de recursos naturais, começam os processos de reciclagem".

Fica evidente que o resíduo é uma importante fonte de renda, para essas associações, porém ainda o maior problema enfrentado está na conscientização da população nas causas ambientais. Muito se ouve falar, mas a prática ainda caminha a passos lentos.

\subsection{Entendimento dos Gestores}

Os responsáveis pelas associações ao serem questionados sobre a participação da prefeitura no processo de coleta seletiva na cidade, as associações responderam o seguinte.

Quadro 7 - Respostas dos gestores das associações sobre a participação da prefeitura

\begin{tabular}{c|l}
\hline Entrevistados & \multicolumn{1}{c}{ Respostas } \\
\hline E1 & $\begin{array}{l}\text { Por enquanto não percebemos os resultados, pois faz pouco tempo que começou esse } \\
\text { sistema de coleta seletiva da prefeitura. }\end{array}$ \\
\hline E2 & Aumentou o número de resíduos recicláveis para a associação, houve melhora. \\
\hline E3 & Não houve melhora, pois há muitos resíduos que não são recicláveis junto com o reciclável. \\
\hline E4 & Deu uma melhorada, no entanto vem muito resíduo não reciclável junto. \\
\hline E5 & Pelo que percebemos não melhorou.
\end{tabular}

Fonte: Dados da pesquisa

Pode-se verificar pelas respostas das associações, que o processo de coleta seletiva realizado pela Prefeitura Municipal de Santa Maria ainda não trouxe resultados visíveis às associações. No entanto, a ARCA, pôde perceber o aumento no número de resíduos recicláveis destinados à associação juntamente com a Associação Noêmia Lazzarini que percebeu um pequeno aumento nos resíduos, mas enfatiza que há muito resíduo não reciclável junto com o reciclável.

Com relação aos dados obtidos no quadro 7 percebe-se que a população não está separando o resíduo adequadamente, colocando muitos resíduos não recicláveis. Acredita-se que esse fator pode ter ocorrido devido à recente existência desse sistema de coleta realizado pelo município.

Alguns indivíduos ainda não conhecem a maneira correta de fazer a separação de resíduo em casa. Segundo Zaneti (1997, p. 14), "mas de nada adiantam campanhas para reciclar e 
programas de coleta seletiva de lixo, se não fizermos um trabalho de internalização de novos hábitos e de atitudes para que, num futuro próximo, não haja mais lixo excessivo".

Parece correto afirmar a partir dos achados que a maior dificuldade está em conseguir aumento na adesão por parte da comunidade santa-mariense, que ainda necessita de mais informações sobre esse processo de coleta seletiva de resíduos.

\subsection{A Questão da Sustentabilidade}

Os responsáveis pelas associações ao serem questionados se o processo de coleta seletiva pode trazer sustentabilidade à associação, responderam o seguinte.

Quadro 8 - Respostas dos gestores das associações a respeito da sustentabilidade à associação

\begin{tabular}{|c|c|}
\hline Entrevistados & Respostas \\
\hline E1 & $\begin{array}{l}\text { Se a coleta seletiva não fosse sustentável, às associações não existiriam. É sustentável sim, } \\
\text { as pessoas são muito consumistas e sempre descartam resíduos que podem ser reciclados. }\end{array}$ \\
\hline E2 & Com certeza, posso afirmar que a coleta seletiva pode trazer sustentabilidade. \\
\hline E3 & $\begin{array}{l}\text { Sim, se todos apoiarem, separarem o material corretamente a coleta seletiva pode } \\
\text { proporcionar sustentabilidade à associação. }\end{array}$ \\
\hline E4 & $\begin{array}{l}\text { Sim, se a prefeitura divulgar para a população a maneira correta de como fazer a separação } \\
\text { do resíduo em casa e conscientizar as pessoas de que isso é o certo a se fazer. }\end{array}$ \\
\hline E5 & $\begin{array}{l}\text { Sim, mas tem que haver a conscientização da população em fazer a separação correta dos } \\
\text { resíduos. }\end{array}$ \\
\hline
\end{tabular}

Fonte: Dados da pesquisa

Percebe-se que é unânime a opinião das associações quando questionado se o processo de coleta seletiva pode trazer sustentabilidade a elas.

Segundo Jacobi (2003), a ideia de sustentabilidade diz que é necessário definir limites às possibilidades de crescimento e traçar um conjunto de iniciativas a fim de levar em conta a existência de interlocutores e participantes sociais relevantes e ativos, reforçando assim um sentimento de corresponsabilidade e de constituição de valores éticos. Com o advento da mídia e as leis de proteção ambiental e destinação correta para os resíduos sólidos, pode-se verificar o porquê da certeza dessas associações em acreditarem que esse processo de coleta seletiva pode trazer sustentabilidade às associações.

\subsection{Aspectos a Melhorar}

Os responsáveis pelas associações ao serem questionados quais aspectos poderiam ser melhorados às associações, responderam o seguinte.

Quadro 9 - Respostas dos gestores das associações a respeito dos aspectos a serem melhorados

\begin{tabular}{c|l}
\hline Entrevistados & \multicolumn{1}{c}{ Respostas } \\
\hline E1 & $\begin{array}{l}\text { A qualidade dos resíduos e a divulgação ampla de como se faz a separação, o que é reciclável } \\
\text { e o que não é, de fácil entendimento a todos. }\end{array}$ \\
\hline E2 & Poderia ser melhorada a divulgação para que mais pessoas selecionem os resíduos. \\
\hline E3 & As pessoas poderiam colaborar mais e separar melhor os resíduos. \\
\hline E4 & $\begin{array}{l}\text { O caminhão da prefeitura poderia vir mais vezes por semana trazendo mais resíduo, e as } \\
\text { pessoas separarem melhor o que é reciclável do que não é, pois mandam muitos resíduos } \\
\text { que não precisamos. }\end{array}$ \\
\hline E5 & Propagandas de conscientização para que as pessoas façam a seleção correta.
\end{tabular}


Percebe-se a insatisfação das associações quanto à qualidade dos resíduos recebidos pelo processo de coleta seletiva, portanto acredita-se que deve haver uma melhor conscientização da população quanto à separação correta dos resíduos.

De acordo com Gioda (2013), as causas das agressões ao meio ambiente são de ordem política, econômica e cultural, a sociedade ainda não absorveu a importância do meio ambiente para sua sobrevivência, pois, a preocupação com o meio ambiente caminha a passos lentos. Verifica-se também a necessidade de uma maior divulgação, incentivando a população a participar do processo de coleta seletiva na cidade e ensinando a fazer a separação correta do resíduo para que facilite o trabalho das associações.

\subsection{Aumentar a Participação da População de Santa Maria em Contribuir com a Coleta Seletiva do Resíduo}

Os responsáveis pelas associações ao serem questionadas, como se poderia aumentar a participação da comunidade com relação aos aspectos de reciclagem, responderam o seguinte.

Quadro 10 - Respostas dos gestores das associações ao serem questionados como se poderia aumentar a participação da comunidade com relação aos aspectos de reciclagem

\begin{tabular}{c|l}
\hline Entrevistados & \multicolumn{1}{c}{ Respostas } \\
\hline E1 & $\begin{array}{l}\text { Cada um se sentindo responsável com o que produz. Conscientização da população. E } \\
\text { sensibilizar a comunidade mostrando que somos a solução para os problemas ambientais e } \\
\text { que eles têm que separar o resíduo corretamente, pois há muito material não reciclável junto } \\
\text { com o reciclável. Assim torna-se mais difícil a separação. }\end{array}$ \\
\hline E2 & $\begin{array}{l}\text { As pessoas já estão conscientizadas de que é importante fazer a seleção correta do resíduo, } \\
\text { mas infelizmente muitos não fazem questão de separar e às vezes mandam resíduos orgânicos } \\
\text { junto. }\end{array}$ \\
\hline E3 & $\begin{array}{l}\text { Mais divulgação para conscientizar, educar a população para esse aspecto de que é } \\
\text { importante fazer a separação do resíduo em casa e ensinar como fazer a separação correta } \\
\text { para não mandarem materiais que não servem para reciclarmos. }\end{array}$ \\
\hline E5 & $\begin{array}{l}\text { O único jeito é a prefeitura comunicar a população da importância da reciclagem, pois isso é } \\
\text { coisa séria. Tem que investir na mídia e mostrar o jeito certo de fazer a seleção do resíduo em } \\
\text { casa. }\end{array}$ \\
\hline $\begin{array}{l}\text { Campanhas de divulgação, publicidade e folders para a conscientização da população e da } \\
\text { importância de se fazer a seleção do resíduo. }\end{array}$ \\
\hline
\end{tabular}

Fonte: Dados da pesquisa

Os resultados indicam a necessidade de uma melhor divulgação da parte da Prefeitura. Exibir com mais clareza a população, o que é e o que não é reciclável. Nota-se a insatisfação das associações quanto a qualidade do resíduo, pois há muitos materiais orgânicos junto com os materiais secos, enfatizando que a população não sabe como separar corretamente.

De acordo com Gutberlet (1998, p.97).

A educação ambiental participativa é um instrumento importante no processo de fortalecimento da cidadania em busca da sustentabilidade, pois propicia conhecimentos e amplia a consciência sobre a situação socioambiental local, tornando o indivíduo um ator responsável.

Acredita-se que com o aumento da participação da população, a educação ambiental e a aprendizagem dos mesmos em selecionarem corretamente seus resíduos, só irão beneficiar as 
associações, fazendo com que elas não deixem de existir. Essa é uma questão bastante relevante visto que são as associações as responsáveis pela destinação correta do resíduo, ajudando assim, a população de Santa Maria a obter uma melhor qualidade de vida e também dando visibilidade a cidade.

Para que ocorra essa participação da população, Bina e Vaz (2011) salientam que as virtudes precisam ser valorizadas como uma dimensão fundamental do que significa ser humano, a partir da forma como educamos as futuras gerações, para que possam contribuir para uma vida que é boa para eles, para o planeta, para todas as crianças e todas as espécies.

Assim, a necessidade é emergente de exibir a população essa mudança necessária de que a coleta seletiva é uma alternativa ecologicamente correta que desvia o destino em aterros sanitários ou lixões, resíduos sólidos que podem ser reciclados. Por essas razões, é imprescindível a participação consciente e assídua da população com o processo de coleta seletiva.

\subsection{Processo Seletivo de Resíduos na Ótica da Prefeitura Municipal de Santa Maria}

Com o advento da Lei 22.305/10 que é a lei da política nacional dos resíduos sólidos, que afirma que cabe ao poder público fomentar e contribuir com a formação e a organização das associações ou cooperativas, segundo o entrevistado fiscal de contratos do Setor do Meio Ambiente, a Prefeitura dá um passo importante no sentido que já está conforme a lei, antes que o ministério cobre dos municípios, a PMSM já está fazendo a sua parte.

O processo "agendado" de coleta, desperta uma conscientização ecológica nos cidadãos, no sentido em que o cidadão passa a entender que também é parte na questão ambiental, uma vez que não compete somente aos órgãos ambientais fiscalizar e licenciar. A própria sociedade passa a enxergar que o poder público está fazendo a sua parte enquanto gestor público.

Conforme o fiscal no qual foi entrevistado, a Prefeitura Municipal de Santa Maria acredita que os novos sistemas de coleta por contêineres e coleta seletiva proporcionam visibilidade à cidade pois a ideia dos contêineres é uma tendência mundial, deixa a cidade mais limpa e organizada. Além de fomentar as associações, a coleta seletiva causa consciência ambiental à população.

Na sua avaliação acredita-se que com o novo processo de coleta seletiva a prefeitura é beneficiada na medida em que vê as políticas públicas em matéria ambiental serem atendidas, bem como, a diminuição do passivo ambiental. Nota-se também que, aos moradores, o benefício é no sentido da reutilização dessa matéria-prima. E para as associações, seria o seu fortalecimento, uma vez que elas deixam de ser exploradas por atravessadores, conseguindo um preço maior para os seus produtos.

De acordo com o entrevistado há preocupação da Prefeitura Municipal de Santa Maria em resolver os problemas com os resíduos sólidos contribuindo com as associações, visto que é de sua responsabilidade, sancionada por lei, fomentar e contribuir com a formação e a organização das associações ou cooperativas.

Segundo Rezende e Castor (2006, p.27):

A gestão urbana pode ser entendida como o conjunto de recursos, instrumentos da administração aplicados na cidade como um todo, visando à qualidade da 
infraestrutura e dos serviços urbanos, propiciando as melhores condições de vida e aproximando os cidadãos nas decisões e ações da governança pública municipal.

Verifica-se que o sistema de coleta seletiva realizado pela Prefeitura é de grande importância à cidade, pois auxilia na organização e o reaproveitamento dos resíduos sólidos, provocando nos cidadãos uma conscientização do quanto é importante a separação do resíduo.

\section{CONSIDERAÇÕES FINAIS}

Com o crescimento da população mundial e o consumismo, as pessoas acabam gerando cada vez mais resíduos e consequentemente descartando-os na natureza. Para evitar consequências catastróficas ao planeta em função da poluição, há um aumento de políticas e práticas de proteção do meio ambiente. Nota-se também, aumento da conscientização ambiental por parte das pessoas, que começam a fazer a separação dos resíduos em suas residências, mas ainda temos muito que aprender e disseminar, sobre os benefícios da coleta e separação seletiva de resíduos.

Percebe-se que com esse sistema de coleta seletiva nas residências, houve aumento da participação da população em separar os resíduos recicláveis dos não recicláveis, dando destaque para a consciência ambiental da população de Santa Maria - RS. No entanto com o grande volume de resíduos não recicláveis encontrados pelas associações, percebe-se que a população não está separando adequadamente. Acredita-se que esse fator pode ser revertido com práticas de divulgação e ensinamentos a população de como separar corretamente.

A separação dos resíduos é uma das soluções para o dilema das preocupações ambientais, pois se verifica a necessidade de enviar para os aterros sanitários somente o resíduo orgânico, enquanto que os secos podem ser conduzidos para a sua reciclagem ou em algumas situações a sua reutilização. Por esse processo, o resíduo volta a ser matéria-prima, para que se poupam recursos naturais e principalmente podendo gerar emprego e renda, como nos casos das associações de catadores em estudo. Todo esse processo evita a deposição de resíduos nos aterros, o que evita a contaminação dos solos e água contribuindo para a sustentabilidade planetária.

O presente estudo que buscou verificar se a coleta seletiva proporciona sustentabilidade às associações participantes possibilitou concluir que o processo adotado pela Prefeitura Municipal de Santa Maria proporciona sim sustentabilidade às associações, bem como proporciona sustentabilidade a população, pois contribui com o meio ambiente proporcionando uma melhoria na qualidade de vida da população.

Apesar de ser um processo árduo e demorado, pois envolve uma mudança comportamental dos santa-marienses, ficou clara a importância da participação da Prefeitura Municipal de Santa Maria, da população e das associações, para que esse processo continue se desenvolvendo e crescendo. A partir destes resultados o presente estudo proporciona contribuições relevantes a todos envolvidos na gestão ambiental.

Estudos futuros podem ampliar as pesquisas sobre o tema verificando não só se o processo de coleta seletiva proporciona sustentabilidade às associações participantes, mas também se a população de Santa Maria encontra-se satisfeita com o serviço prestado, ou até mesmo se haverá mais associações sendo beneficiadas com esse sistema de coleta. 


\section{REFERÊNCIAS}

1. ANDRADE, R. O. B. , et al. Gestão Ambiental: enfoque estratégico aplicado ao desenvolvimento sustentável. 2. ed. rev. ampl. São Paulo: Makron, 2002.

2. BARBIERI, J. C. Gestão Ambiental Empresarial: conceitos, modelos e instrumentos. 3 Ed. São Paulo: Editora Saraiva, 2011.

3. BARDIN, L. Análise de conteúdo. Editora: edições 70: São Paulo, 2010.

4. BINA, O.; VAZ, S. G. Humans, environment and economies: from vicious relationships to virtuous responsibility. Ecological Economics, 72, (2011), 170-178.

5. BULOS, U. L. Constituição Federal Anotada. São Paulo: Saraiva: 2003.

6. DIAS, R. Gestão Ambiental: responsabilidade social e sustentabilidade. 1 Ed. São Paulo: Atlas, 2005.

7. DONAIRE, D. Gestão Ambiental na Empresa. 1 Ed. São Paulo: Atlas, 2009.

8. FLORIANO, E. P. O Desenvolvimento de uma Economia Sustentável. Santa Rosa: Ambiente Interno, 2007.

9. GIL, A. C. Como Elaborar Projetos de Pesquisa. 5 ed. São Paulo: Atlas, 2010.

10. GIODA, A. Gestões Ambientais. Temos consciência da influencia dos mesmos em nossas vidas? 2013. Disponível em: <http://www.terrabrasil.org.br/noticias/materias/pnt_proble masamb.htm>. Acesso em: jan. de 2013.

11. GOMES, F. A. A História da Degradação Socioambiental. 2008. Disponível em: < http://www.contraversao.com.br/index.php?option=com_content\&view=article\&id=73:ahistoria-da-degradacao-socioambiental\&catid=28:meio-ambiente\&ltemid=56>. Acesso em: jan. 2012.

12. GUTBERLET, J. Desenvolvimento desigual: impasses para a sustentabilidade. São Paulo: Konrad - Adenauer Stiftung, 1998.

13. IBGE 2010. Censo Demográfico 2010. Disponível em: <http://www.ibge.gov.br/cidadesat/link. php?uf=rs>. Acesso em: dez. 2012.

14. JACOBI, P. R. Ciência Ambiental: os desafios interdisciplinares. São Paulo: Annablume, 2003.

15. OLIVEIRA, S. L. de. Tratado de Metodologia Científica: Projetos de Pesquisas, TGI, TCC, Monografias, Dissertações e Teses. São Paulo: Pioneira Thomson Learning, 2001.

16. REZENDE, D. A.; CASTOR, B. V. J. Planejamento estratégico municipal: empreendedorismo participativo nas cidades, prefeituras e organizações públicas. 2ª Ed. Rio de Janeiro: Brasport, 2006.

17. SCHARF, R. Manual de Negócios Sustentáveis. São Paulo: Amigos da Terra, 2004.

18. SOUZA, M. R. de; SILVA, M. J. A Geração de Resíduos Industriais e sua Destinação Final. ENEGEP, 1997. Disponível em: <http://www.abepro.org.br/biblioteca/ENEGEP1997_T6501 .PDF>. Acesso: 18 jun. 2012.

19. TACHIZAWA, T.; MENDES, G. Como fazer monografia na prática. 5. ed. Rio de Janeiro: Editora FGV, 2000.

20. TACHIZAWA, T. Gestão Ambiental e Responsabilidade Social Corporativa: estratégias de 
negócios focadas na realidade brasileira. São Paulo: Atlas, 2009.

21. TAYRA. Flávio. O conceito de desenvolvimento Sustentável. In: Revista de economia e desenvolvimento sustentável, n. 0, jun./2007. (Edição Experimental).

22. VALLE, C.E. Qualidade Ambiental: como ser competitivo protegendo o meio ambiente: (como se preparar para as Normas ISO 14000). São Paulo: Pioneira, 1995.

23. Qualidade Ambiental: ISO 14000. 12a Ed. São Paulo: Editora Senac São Paulo, 2012.

24. YIN, R. K. Estudo de Caso: planejamento e métodos. 3ạ Ed. Porto Alegre: Bookman, 2005.

25. ZANETI, I. Além do Lixo. Reciclar um processo de transformação. Brasília: Terra Uma, 1997. 